\title{
Thunderstorm Electrical Parameters vis-à-vis Rainfall and Surface Air Temperatures over a Tropical Inland Station, Pune, India
}

\author{
Md. Iqbal R. TINMAKER, Kaushar ALI and Sunil D. PAWAR \\ Indian Institute of Tropical Meteorology, Pune, India \\ (Manuscript received 19 November 2009, in final form 3 September 2010)
}

\begin{abstract}
The relationship of lightning with rainfall and temperature is investigated on the basis of a four-year (20042007) data set over the Pune region. It is found that the annual variations of stroke count and rainfall both are bimodal with the first peak value of rainfall showing a one month time lag from the first peak value of stroke count. This is attributed to the prime period of the onset phase of summer monsoon rainfall over the Pune region. Lightning is found to be highly correlated with rainfall $(r=0.792$, significant at $0.4 \%)$, but by excluding the data for the month of July. The annual variation in the monthly mean surface wet bulb temperature and stroke count for the period under study over the Pune region shows similar peaks in June and September. These two parameters are well-correlated and show a positive correlation coefficient of 0.59 , which is significant at the $5 \%$ level. A massive reduction in the lightning stroke count during July and August is attributed to low ground temperature that gives rise to lower updraft velocities and shallower cloud depth. There is good parallelism in the variation of surface air temperature and Point Discharge Current (PDC). The correlation coefficient between these two parameters is 0.934 , and it is highly significant.
\end{abstract}

\section{Introduction}

Lightning and related rainfall are important weather phenomena over the Indian region, particularly during the pre-monsoon (March-May) and post-monsoon (October-November) seasons. The importance lies in the fact that lightning is associated with thunderstorms that contribute substantially to the annual total rainfall over the Indian region. In addition, the investigation on this aspect of lightning will be helpful in understanding several implications related to the growth of thunderclouds and their electrification. The measurement of lightning flash count in thunderstorms is useful to estimate lightning intensity, which in turn provides information on dynamics and microphysics of convective storms. For example, the intensity can give information on the stage of convective cloud devel-

Corresponding author: Dr. Kaushar Ali, Indian Institute of Tropical Meteorology, Dr. Homi Bhabha Road, Pashan, Pune-411 008, India.

E-mail: kaushar@tropmet.res.in

(C) 2010, Meteorological Society of Japan opment (Williams et al. 1989), the intensity of the updraft (Lhermitte and Williams 1983), the cloud liquid water content (Saunder et al. 1991) and the cloud structure (Rust and Doviak 1982).

Moist convection is a crucial atmospheric process for the development of thunderstorm clouds and lightning. It incorporates the effect of both heat and moisture simultaneously. Since wet bulb temperature represents the effect of heat and moisture simultaneously, it is pertinent to investigate the relationship between lightning and wet bulb temperature. There have been some studies on this aspect of tropical regions (Williams et al. 1992; Williams 1992, 1994, 1997; Jayaratne 1993), which show that lightning flash rate has a direct relationship with wet bulb temperature.

It is well-documented that the ice particle collisions in the mixed phase region of a thundercloud are the primary drivers for both cloud electrification and PDC. The value of PDC is determined by cloud dynamics and microphysics that play an important role in cloud electrification by noninductive charging mechanism. Williams 1989, and 
Toracinta and Zipser 2001 very well describe, in brief, the non-inductive charging mechanism for cloud electrification. According to them, charge transfer occurs during non-inductive collisions between small and large ice particles (i.e., graupel or hail) in the presence of super cooled liquid water in the mixed phase region of the cloud (where $0^{\circ} \mathrm{C} \geq$ $T \geq-40^{\circ} \mathrm{C}$, where $T$ is the temperature). The magnitude and sign of the charge transferred during individual ice-ice collisions, which are governed by several environmental parameters (i.e., temperature, super cooled liquid water content, ice particle size, and differential velocity) are sufficient to account for space charge densities and vertical charge structure in the thunderstorms.

The most important ground facts for the possible development of a thunderstorm cloud are the availability of moist air at the ground surface and the sun-heated hot land surfaces. In the absence of well-heated hot land surfaces, with low mean air temperatures, just damp air alone is not likely to promote the development of a thunderstorm cloud (Williams and Renno 1993). It is therefore important to investigate the degree of relationship between surface air temperature and PDC to understand the electrification of the thunderstorm clouds. Only one study has been undertaken so far for the Pune region on the association between surface air temperature and PDC (Manohar et al. 1999). The study has shown a high correlation $(r=0.92$, highly significant) between these parameters on seasonal time-scales. The present study also aims at investigating the association between surface air temperature and PDC using the latest data for Pune on monthly time-scales.

Apart from research perspectives, understanding lightning and associated rainfall is also important from the application point of view. We know that lightning is hazardous to aviation (Awadesh 1992). Knowledge on the various aspects of lightning may help meteorologists to develop its forecast model that can be very useful for forecasts along aviation routes. The electromagnetic field that incites lightning strikes in a thunderstorm can pose a serious problem and threat to sensitive electronics in production systems, transmission equipment, and household appliances. Though the forecast model cannot completely solve such problems, it can at least provide anticipation to avoid the threat. Thus, precise knowledge about lightning in thunderstorms makes a large contribution to effective damage reduction in many application areas. Ra- dio frequencies (from $\mathrm{kHz}$ to $\mathrm{GHz}$ ), used in relay and transmission systems, are attenuated and interfered with precipitation particles in the thunderstorm and the associated lightning. This causes fading of the signals and limits the utility of receiver systems. Knowledge of the climatology of thunderstorm and lightning occurrences over a region can help in the economical design of electronic reception systems that can absolve from such fading of the signals.

Considerable prior research work on various aspects of thunderstorm and lightning carried out over the globe is available (Sohoni 1931; Rao and Raman 1961; Raman and Raghavan 1961; Williams 1961; Chaudhury 1961; Rao et al. 1971; Balogun 1981; Oladipo and Mornu 1985; Prasad and Pawar 1985; Sivaramkrishnan 1990; Price and Rind 1994; Moid 1995; Williams et al. 2004). On the basis of thunderstorm data, few attempts have been made to understand thunderstorm climatology, lightning-rainfall relationships, the relationship between lightning and Convective Available Potential Energy (CAPE) and the relationship between thunderstorm activity and wet bulb temperature (Manohar et al. 1999; Kandalgaonkar et al. 2005a, b; Manohar and Kesarkar 2005). The measurement techniques and regions for the lightning data in these studies are different. The period of study also varies from one day to a year.

The climatological studies on thunderstorms made over the Indian region by Kandalgaonkar et al. (2003) have shown that the maximum lightning activity occurs in the month of May with a superimposed diurnal maximum at 1330IST (0800UTC). Manohar and Kesarkar (2005) have examined the spatio-temporal thunderstorm activity along the east and the west coasts across the Indian peninsula and have shown that the east coast experiences higher thunderstorm activity, which varies with latitude. Kandalgaonkar et al. (2005a) have examined spatio-temporal variability of the lightning activity over the Indian region. They have found that lightning activity has direct nonlinear relation with latitude. The nonlinearity in their relation occurs due to the land mass distribution, orography and large-scale circulations.

Because of various research- and applicationoriented needs of lightning stroke as mentioned above, an effort is made in the present study to investigate the relationship between lightning and rainfall in the thunderstorm, between lightning and surface wet bulb temperature, and between point 


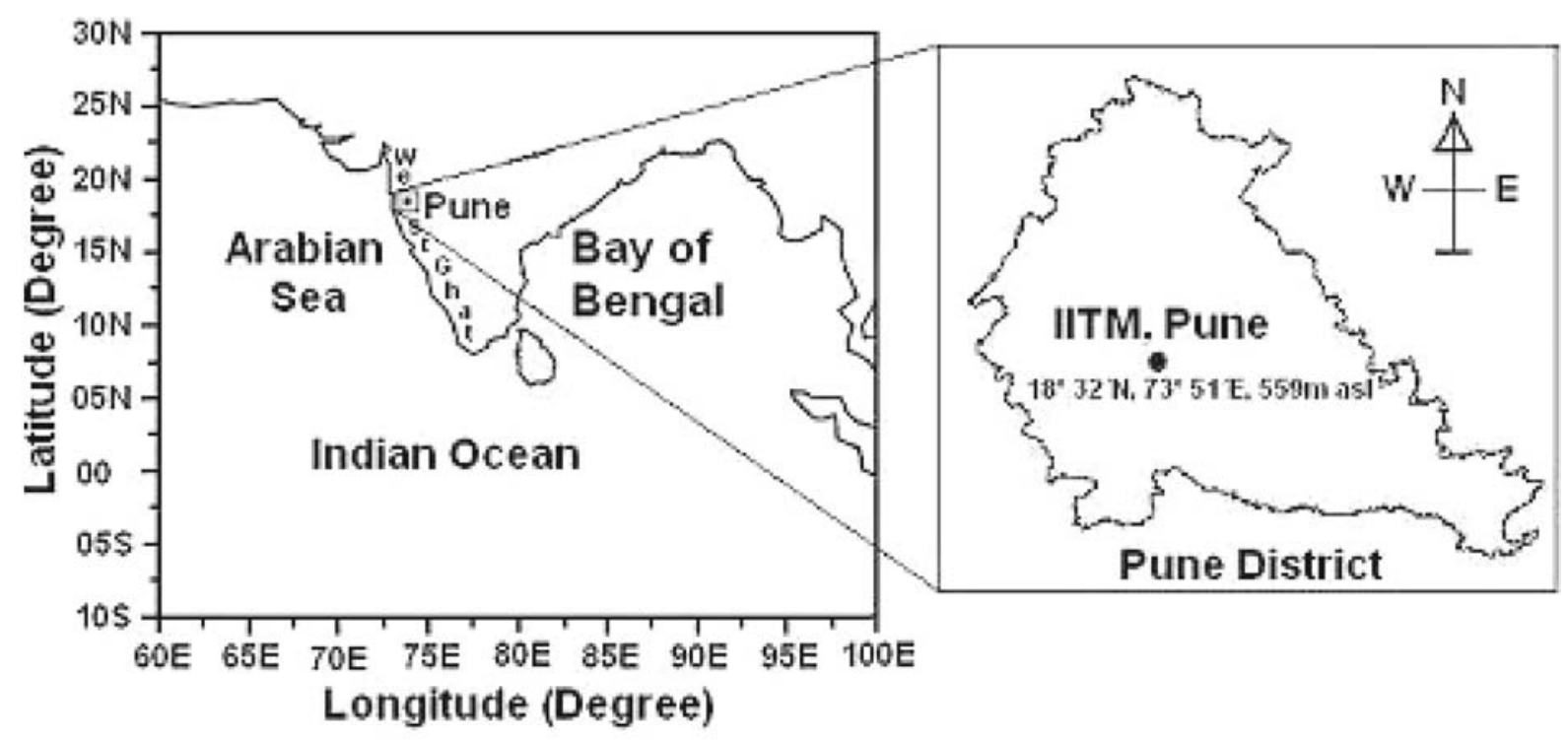

Fig. 1. Map showing the Pune region

discharge current (PDC) and the maximum temperature of surface air.

\section{Data}

The domain of the present study is the tropical inland station at Pune $\left(18^{\circ} 32^{\prime} \mathrm{N} ; 73^{\circ} 51^{\prime} \mathrm{E}, 559 \mathrm{~m}\right.$ asl as shown in Fig. 1), which lies on the lee side of the Western Ghats. A four-year archive (20042007) of lightning stroke count, rainfall, surface air temperature and wet bulb temperature forms the data set for the study. The lightning stroke count data are obtained with the help of a Boltek Storm Tracker installed at IITM, Pune, whereas the temperatures and the rainfall data are obtained from the India Meteorological Department. The point discharge current data used in the present study are available only for the period of April-October, 1998 and were obtained by a point discharge needle installed at the terrace of the institute's building of IITM, Pune. Details of the measurement technique for PDC are available elsewhere (Kandalgaonkar et al. 2001).

\section{Instrumentation}

The main equipment used for detecting lightning in thunderstorms is a Boltek Storm Tracker as shown in Fig. 2. It is installed on the terrace (nearly $40 \mathrm{ft}$ above the ground level) of the Indian Institute of Tropical Meteorology (IITM), Pune $\left(18^{\circ} 32^{\prime} \mathrm{N}\right.$, $73^{\circ} 51^{\prime} \mathrm{E}, 559 \mathrm{~m}$ asl), India, as shown in Figs. 1, 2. It uses a crossed-loop antenna to determine the di- rection of the lightning and its signal strength that are further used to calculate an approximate distance of the lightning. The instrument measures low frequency $(<500 \mathrm{kHz})$ radio signals produced by lightning's electrical discharge. It detects both the cloud-to-ground (CG) and the intra-cloud (IC) lightning discharge, and it can discriminate between positive and negative strokes from characteristics in the signal waveform (Davis and Lo 2008). The lightning detection range of the equipment is variable with a maximum range of 300 miles. The instrument has two built-in alarms: (i) the close storm alarm, and (ii) the severe storm alarm. The close storm alarm is activated when a thunderstorm is detected closer than the preset distance and the severe storm alarm is activated when the number of lightning strikes per minute exceeds the preset limit. Once the instrument determines the distance and the direction, the software automatically plots them on a real time map.

The Storm Tracker includes a software package, Lightning 2000, that processes all the available sensor information in real time and computes a separate location for each individual stroke in the flash. The lightning stroke data are logged on the hard disk of the computer. Thus, the Storm Tracker detects where the lightning is, receives an early warning of developing and approaching thunderstorm, provides information about direction and nearness of the thunderstorm, follows developing and decaying storms and archives all data on the computer 


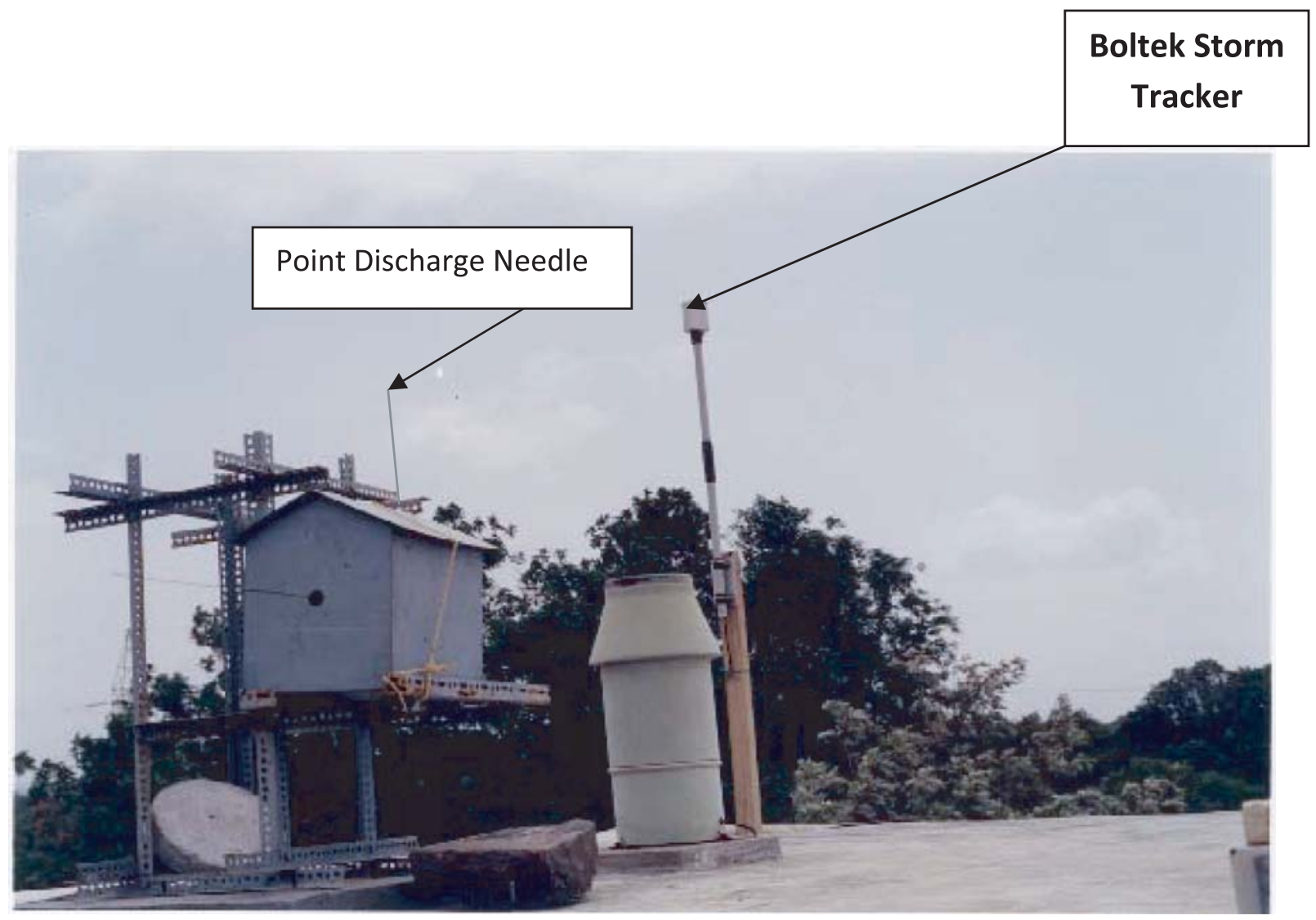

Fig. 2. System of Boltek Storm Tracker installed on the terrace of IITM, Pune

for further analyses. The manufacturer has estimated detection efficiency of the hardware with data sets from several storms. The efficiency is $85 \% \pm 6 \%$ for $\mathrm{CG}$ and $20 \% \pm 6 \%$ for IC.

The main objective of the measurements of lightning stroke parameters was to investigate some of their statistical features and associated rainfall in thunderstorms over a limited spatial region of Pune. Accordingly, the instrument was set for a lightning detection range of $10 \mathrm{~km}$ around IITM, Pune and the data were archived with minimum archiving speed for accuracy in the stroke counting. On account of the fact that the detection efficiency of the instrument for IC is much less, the lightning stroke data used in the present study relate only to $\mathrm{CG}$ lightning stroke.

\section{Meteorological condition}

The development of thunderstorms and associated lightning in a region depends mainly on the meteorological condition of the region. Hence, it is pertinent to highlight the general meteorological condition controlling different weather feature occurrence in the Pune region. This will facilitate the understanding of the results. Depending upon the prevailing meteorological condition and weather feature occurrence during different periods of the year in India, the year has been divided by the India Meteorological Department in to four seasons namely, (a) Pre-monsoon season (March-May), (b) Monsoon season (June-September), (c) Postmonsoon season (October-November), and (d) Winter season (December-February). A brief summary of the meteorological condition and the weather occurring during different seasons at Pune is given below:

\section{(a) Premonsoon}

The weather during the pre-monsoon season is very hot and relatively dry with the daytime maximum temperature showing day-to-day variation in the range of $38^{\circ}$ to $42^{\circ} \mathrm{C}$. Climatologically, the 
average maximum temperature during pre-monsoon is $\sim 39^{\circ} \mathrm{C}$ (Anonymous 2005 ). Nighttime conditions are cool due to the sea breeze circulating from the Arabian Sea to the region (IMD 1931). Surface winds are mostly gusty and cumulonimbus development takes place occasionally during the afternoon and evening hours. The dust content is the maximum during this season.

\section{(b) Monsoon}

During the monsoon, southwesterly and westerly winds rich in marine air from the Indian Ocean and the Arabian Sea prevail over the region. Weather in this season is wet and humid. The region receives light but continuous or intermittent rain from cumulus and stratocumulus clouds under the influence of large-scale convergence due to synoptic systems. Occasionally, nimbostratus clouds rain heavily in the region on the establishment of the monsoon over the region. Normal rainfall of the area during monsoon season is $560 \mathrm{~mm}$, which constitutes about $80 \%$ of the annual rainfall. Setting of monsoon over the region starts with thunderstorm and lightning. Also, when there is revival of monsoonal activity after a break period, there is thunderstorm occurrence over the region.

\section{(c) Post-monsoon}

Because of the cessation of rainfall activity after September, the average daily temperature increases. The westerly flow weakens in the lower troposphere and the easterly flow sets in accompanied by a rapid fall in the minimum temperature by the end of October. During October, the days are hot and the nights are cool. The remnant of the monsoon period's humidity and the daytime heating paves the way for the development of thunderstorm during October. However, the chance development of thunderstorms decreases due to moisture deficiency and low Sun as the season progresses.

\section{(d) Winter}

There is further decrease in the surface air temperature with the commencement of the winter season. Climatologically, the minimum temperature is around $12^{\circ} \mathrm{C}$ and the maximum temperature is around $30^{\circ} \mathrm{C}$. The morning (0830IST or 0500UTC) relative humidity $(\mathrm{RH})$ is usually $>70 \%$, and the evening (1730IST or 1200 UTC) $\mathrm{RH}$ is $<35 \%$. Surface winds are light and less gusty. The weather condition is fair and normally characterized by clear sky and low average relative humidity (about $45 \%$ ).

\section{Results and discussions}

\subsection{Annual variation of stroke count and rainfall over Pune region}

Figure 3 shows the annual variation of stroke count and rainfall based on their monthly average amounts. The vertical bars about the months' average values shown in the figure represent the standard deviations. It is clear from the figure that the stroke count increases consistently from the minimum value of 21 strokes/year in the month of January to 360 stroke/year in the month of May and thereafter increases rapidly to attain a peak in the month of June (1491 strokes/year). It then decreases until August and reaches a low value of 103 strokes/year. A second higher peak in the lightning stroke count is observed in the month of September (2342 strokes/year). After September, the lightning activity diminishes and becomes very low (40 strokes/year) in the month of December. Standard deviations about the mean values of the lightning stroke and rainfall of the individual months are generally low. Only during the months when peaks have occurred, the standard deviations are a little high, though statistically not significant. This implies that there is consistency in the occurrences of annual number of lightning stroke and the annual amount of rainfall spread over the period under study. The two peaks in the variation of the number of lightning stroke count may be explained on the basis of the prevailing synoptic condition over the region. During June and September, the winds in the lower troposphere of the Pune region become more westerly, and this brings ample moisture over the region from the Arabian Sea. The moisture injected into the atmosphere at $1-3 \mathrm{~km}$ acts as a trigger for the development of cumulus clouds. These clouds grow to thunderclouds on a number of occasions due to intense development of conditional instability and subsequently produce lightning discharges (IMD 1931).

The annual variation of average rainfall in Fig. 3 shows a systematic increase similar to the stroke count. The minimum rainfall, nearly equal to zero, is recorded in the month of January. It increases slowly up to March $(5.3 \mathrm{~mm})$ and then grows to reach a peak value in the month of July $(\sim 187 \mathrm{~mm})$. Further, the rainfall activity decreases. However, a second maximum $(150 \mathrm{~mm})$ in the annual variation of rainfall is recorded in the last month of the monsoon season (September). The activity becomes much less onwards and causes a 


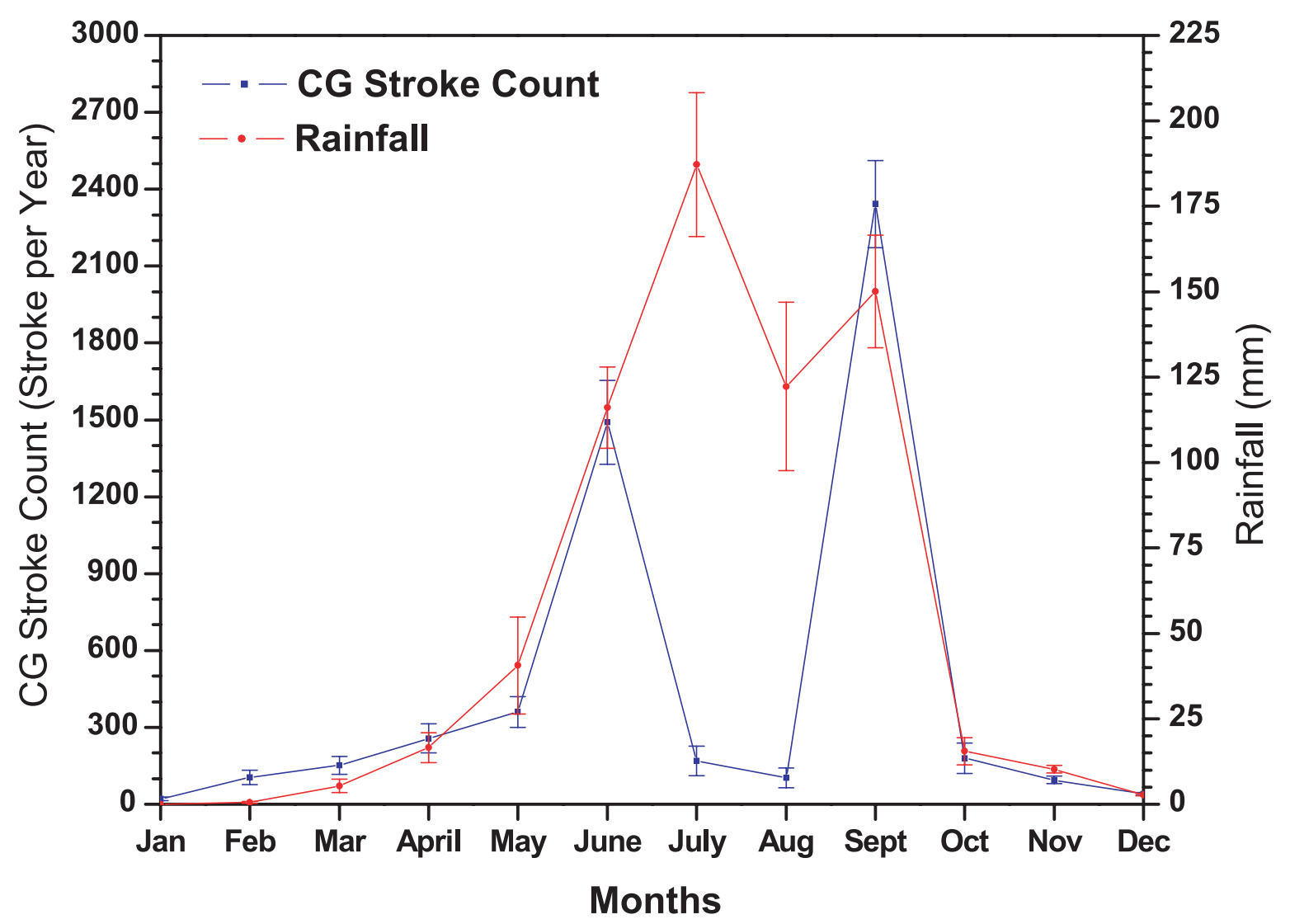

Fig. 3. Annual variations in stroke count and rainfall over the Pune region (vertical bars represent the standard deviation)

low rainfall value equal to $2.8 \mathrm{~mm}$ in the month of December. Thus, there is nearly co-variation of rainfall with the number of stroke counts throughout the year except from June to July when both the quantities show an opposite phase of variation. The correlation coefficient between the two variables is 0.551 (result is not significant at $5 \%$ ). On excluding the data for July from these variations, the correlation coefficient is highly enhanced $(r=$ 0.792 , significant at better than $0.4 \%$ ).

The figure suggests that the first peak rainfall activity happens to occur one month later than the first peak activity of the lightning stroke. The onemonth time lag in the peak rainfall activity is attributed to the prime period of the onset phase of the summer monsoon rainfall over the Pune region. The pre-onset period is associated with intense solar heating over the Pune region. The atmosphere becomes unstable mainly due to intense convection. When marine air from the Arabian Sea enters the region during June, the atmosphere becomes highly unstable due to availability of moisture above the lower troposphere. Thus on account of development of intense conditional instability over the region, the growing clouds rise to above freezing level and ice process becomes effective. Consequently, the thunderstorms that develop during June have high value of CAPE giving rise to peak lightning flash count (Manohar et al. 1999).

As the monsoon, activity settles over the region during July, the atmosphere becomes wet because of widespread cloudiness resulting from the continuous supply of moisture from the Arabian Sea. Thermal heating diminishes. Even on revival of the monsoon activity after the break during the monsoon months, the convection is not always effective in transporting moisture above the freezing level. Maritime clouds with moderate updrafts prevail over the region causing minimum cloud electrification. This is supported by a study made by Takahashi (1990) for Micronesian thunderstorms. Under such circumstances, the warm rain process becomes 


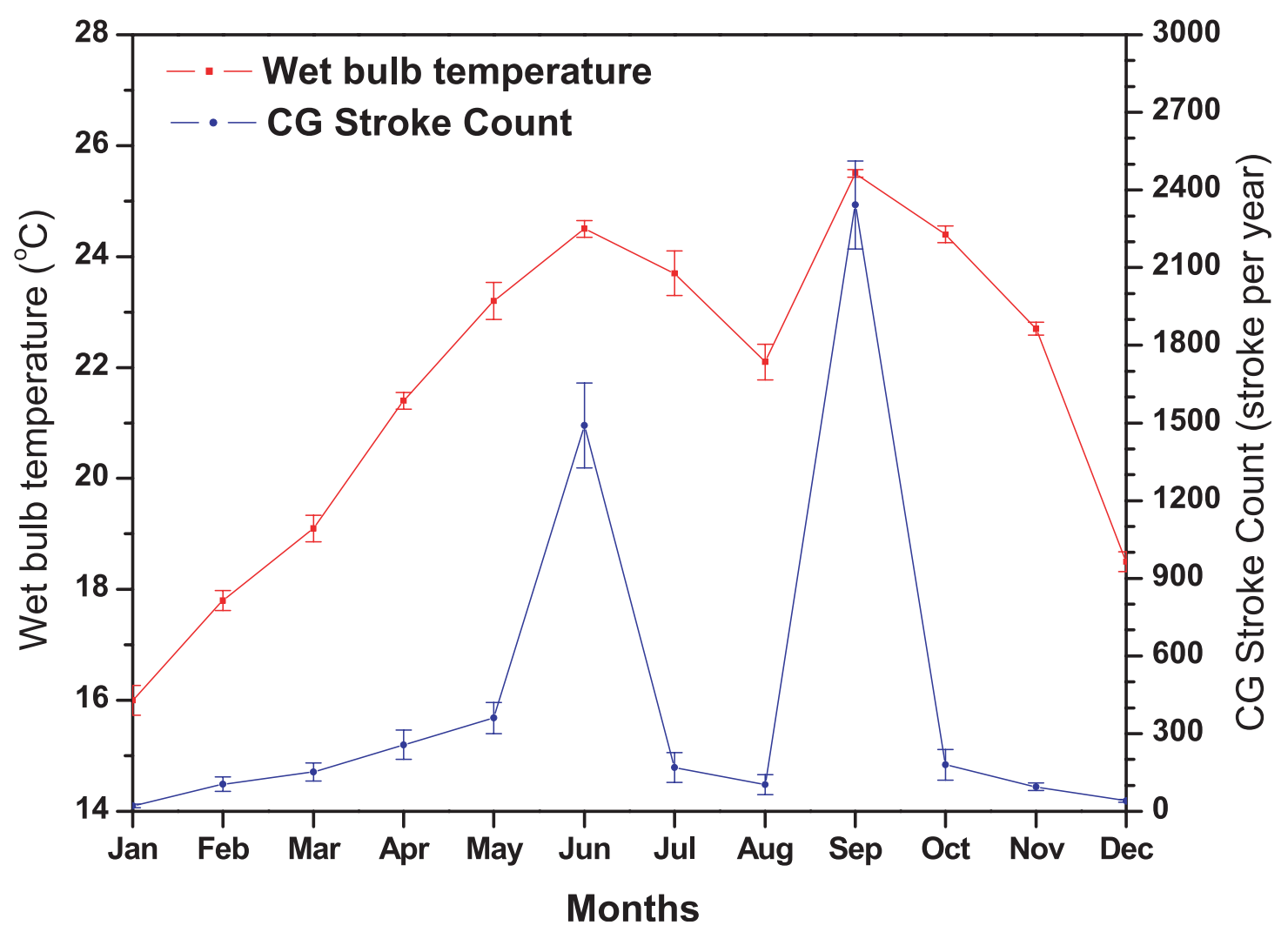

Fig. 4. Variation of surface wet bulb temperature and stroke count over the Pune region (vertical bars represent the standard deviation)

effective in the thunderstorm development over the Pune region and so the lightning flash count decreases in July. Atmospheric condition during August remains similar to that during July. Therefore, the chance for development of thunderstorms and lightning during these two months is similar and much reduced (Jenamani et al. 2006, Zipser 1994).

The occurrence of a higher peak of lightning stroke in the month of September than in the month of June may be due to the difference in physical states of the clouds during the two months caused by the prevailing meteorological conditions. The cloud bases of the thunderstorms occurring in September are normally at lower heights than those occurring in May and June (Manohar and Kandalgaonkar 1995). Thus, lower cloud base height may be one of the reasons for more number of stroke counts in September than in May and June. Another reason for larger number of stroke counts in September than in June is the monsoon withdrawal phase of the southwest monsoon and the onset of the northeast monsoon over the region. Due to monsoon withdrawal in September, regular clouds and rainfall activity ceases. The earth's surface intercepts more solar radiation than that received during the other monsoon months. At the same time, there is still availability of sufficient moisture in the atmosphere to sustain thunderstorm development caused by local solar heating. On the other hand, in spite of intense or moderate convection during the pre-monsoon months and the beginning of June caused by solar heating (Kandalgaonkar et al. 2008), there is lack of sufficient moisture during these periods. Therefore, the chance for development of thunderstorms during these months is less than that in September.

The plot of annual variation of wet bulb temperature shown in Fig. 4 exhibits the highest peak in the month of September. This is suggestive of the occurrence of the highest value of the CAPE during this month (Williams and Renno 1993) and it supports the concept of increased interception of solar 
radiation by the Earth and the availability of ample moisture in the atmosphere in September.

\subsection{Annual variation of stroke count and wet bulb temperature over Pune region}

Figure 4 shows annual variation of monthly mean surface wet bulb temperature and CG stroke count (with their standard deviations about the means) over the Pune region during the period under study. The wet-bulb temperature and stroke count show a similar trend of variation from January to December with two peaks- one in the month of June and the other in September. The variation in the wet bulb temperature tracks closely with the variation in the stroke count. The stroke count shows a large fluctuation between June and September (i.e., during monsoon months), whereas there is comparatively little fluctuation in the wet bulb temperature. The correlation coefficient between these two parameters is 0.59 , which is significant at the $5 \%$ level of significance. Therefore, wet bulb temperature may be a good indicator for the thunderstorm lightning activity over the region.

Excluding the values of the variables for July and August, the correlation coefficient is improved to 0.66 , which is significant and better than $4 \%$. Exclusion of these values from the correlation analysis implies ignoring the impact of advectively transported marine moist air over the Pune region and low ground temperature of the region, which happen to occur during these two wet months. Low ground temperature during these months gives rise to lower updraft velocities, causing the development of only shallower clouds. Consequently, the chance for the development of thunderclouds is reduced. The wet bulb temperature dip too during July and August but not to a very large extent. Thus, both the variables migrate in the same phase even during July and August. Nevertheless, because of the difference in the degree of migration of the two variables during these wet months, the value of the correlation coefficient between the two variables becomes less when the analysis includes the data for the two wet months also.

\subsection{Variation in PDC and surface air maximum temperature from April to October}

Figure 5 shows the mean value of PDC for individual months from April to October and climatological mean values of the maximum temperature at Pune. Mean PDCs of individual months are estimated on the basis of the sum of the mean PDCs measured in individual thunderstorm events occur- ring in a month divided by the number of thunderstorm events in that month. The plot depicts that there is good parallelism in the variation of these two parameters from April to August. The correlation coefficient between maximum temperature and PDC estimated over the whole gamut of the data comes as 0.934 , which is significant at $0.3 \%$ level. That is, as the temperature decreases from April to August, the PDC also decreases, but with a lower rate. The average PDC gradient with respect to maximum temperature during these months comes as $0.068 \mu \mathrm{A} /{ }^{\circ} \mathrm{C}$. Afterwards, the maximum temperature and PDC both increase until September. The gradient of PDC from August to September is $0.2 \mu \mathrm{A} /{ }^{\circ} \mathrm{C}$, which is about three times more than what comes for earlier months. The higher value of PDC gradient from August to September is caused by an increase in the strength of moist convection due to slight increase in the daily average temperature. Thus, conditional instability that normally drives thunderstorm and lightning during September is more important than convective instability during dry periods as far as cloud electrification is concerned. Another important point is that there is a negative PDC gradient of $-0.5 \mu \mathrm{A} /{ }^{\circ} \mathrm{C}$ after September, because as temperature increases from September to October, PDC decreases. This result is attributed to the lack of sufficient moisture in the atmosphere and low solar heating in comparison to the drier pre-monsoon months.

The parallelism in the variation of lightning flash count and climatological mean maximum temperature implies that the value of PDC may be determined by cloud dynamics and microphysics, which play an important role in cloud electrification by non-inductive charging mechanism.

\section{Concluding remarks}

The present study is an analysis of lightning stroke count in terms of its association with rainfall, wet bulb temperature and point discharge current using four years (2004-2007) of lightning stroke data collected at Pune with the help of a Boltek Storm Tracker. The analysis has shown the following principal results:

(i) Peak monsoonal rainfall activity that occurs during July lags behind the first peak of lightning stroke activity by a month. This is attributed to the prime period of the onset phase of summer monsoon rainfall over the Pune region.

(ii) Wet bulb temperature may be a good indicator for the thunderstorm lightning activity as the 


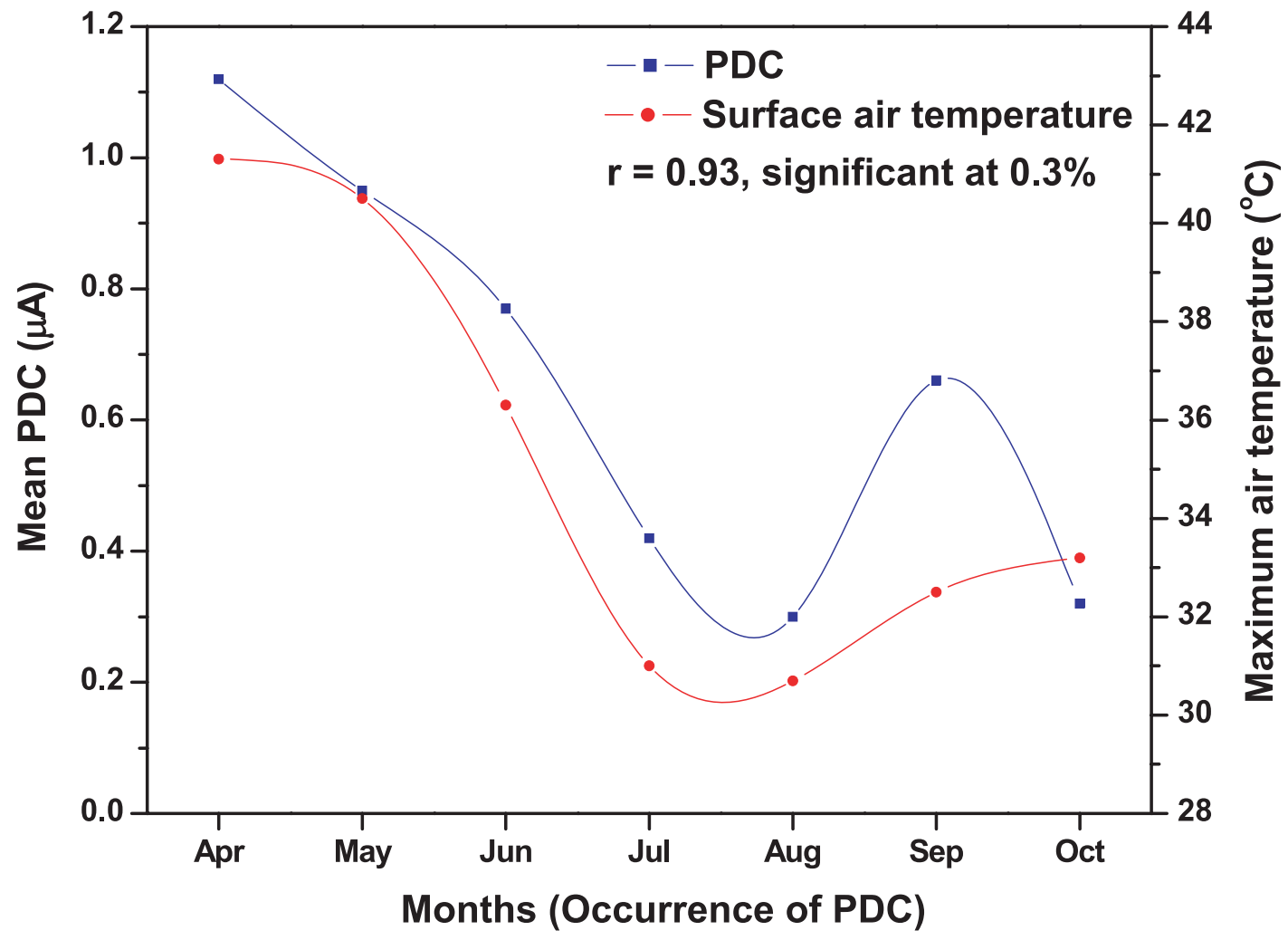

Fig. 5. Surface air temperature (Max) and Point Discharge Current (PDC) during thunderstorms for the year 1998 at Pune

correlation coefficient between these two parameters is 0.59 , which is significant at the $5 \%$ level of significance.

(iii) There is good parallelism in the variation of surface air temperature and PDC. Correlation coefficient between these two parameters is 0.934 , which is significant at the $0.3 \%$ level.

(iv) Similar results on the association of the thunderstorm electrical parameters with the rainfall and the surface air temperatures may be expected for nearly all the inland Indian Peninsular regions off the Arabian Sea due mainly to their geographical, topographical and orographic similarities.

\section{Acknowledgements}

The authors are thankful to Professor B. N. Goswami, Director, IITM, Pune, for his kind support and valuable guidance to this work. The help received from Professor Earle Williams of Massachausettes Institute of Technology on several occasions during the progress of this work is worth mentioning. The authors thankfully acknowledge him.

\section{References}

Anonymous, 2005: Climate of Maharashtra, India Meteorl. Dept. Publication.

Awadesh, K., 1992: A climatological study of thunderstorms at Lucknow airport. Mausam, 43, 441-444.

Balogun, E. E., 1981: Seasonal and spatial variation of thunderstorm activity over Nigeria Weather, 36, 192-197.

Chaudhury, A. K., 1961: Premonsoon thunderstorms in Assam, Tripura and Manipur. Indian J. Meteorol. Geophys., 12, 1, 33-36.

Davis, C. J., and Kin-Hing Lo, 2008: An enhancement of ionospheric sporadic-E layer in response to negative polarity cloud-to-ground lightning. Geophys. Res. Lett., 35, L05815, doi:10.1029/2007GL031909.

India Meteorological Department, 1931: The structure of the sea-breeze at Poona, Scientific Notes, Vol. 3, No. 30, 131-134.

Jenamani, R. K., S. C. Bhan, and S. R. Kalsi, 2006: Observational/forecasting aspects of the meteorological event that caused a record highest rainfall in Mumbai. Curr. Sc., 90, 1344-1362.

Kandalgaonkar, S. S., M. K. Kulkarni, and M. I. R. Tinmaker, 2001: Time evolution and frequency distri- 
bution of point discharge current. J. Atmos. Electricity of Japan, 21, 2, 95, 100.

Kandalgaonkar, S. S., M. I. R. Tinmaker, J. R. Kulkarni, and A. Nath, 2003: Diurnal variation of lightning over the Indian region, Geophys. Res. Lett., 30(20), 2002, doi:10.1029/2003GL018005.

Kandalgaonkar, S. S., M. I. R. Tinmaker, J. R. Kulkarni, A. Nath, and M. K. Kulkarni, 2005a: Spatio-temporal variability of lightning activity over the Indian region. J. Geophys. Res., 110, D11108, doi:10.1029/2004JD005631.

Kandalgaonkar, S. S., M. I. R. Tinmaker, A. S. Nath, M. K. Kulkarni, and H. K. Trimbake, 2005b: Study of thunderstorm and rainfall activity over the Indian region, Atmosfera, 18, 91-101.

Kandalgaonkar, S. S., M. I. R. Tinmaker, and M. K. Kulkarni, 2008: Two year observational study of lightning and rainfall activity over Pune, India, International J. Meteor., 33, 39-48.

Lhermitte, R., and E. R. Williams, 1983: Cloud electrification, Rev. Geophys., 21, 984-992.

Manohar, G. K., and S. S. Kandalgaonkar, 1995: Estimation of electrical charges deposited to the ground by lightning in thunderstorms at Pune. Ind. J. Radio and Space Phys., 24, 297-307.

Manohar, G. K., S. S. Kandalgaonkar, and M. I. R. Tinmaker, 1999: Thunderstorm activity over India and the Indian southwest monsoon. J. Geophys. Res., 104, D4, 4169-4188.

Manohar, G. K., and A. P. Kesarkar, 2005: Climatology of thunderstorm activity over the Indian region: III. Latitudinal and seasonal variation. Mausam, 56, 3, 581-592.

Moid, S. A., 1995: "A climatological study of thunderstorms at Mohanbari Airport. Mausam, 46, 202204.

Oladipo, E. O., and M. E. Mornu, 1985: Characteristics of thunderstorms in Zaria, Nigeria Weather, 40, 316-322.

Prasad, S. K., and B. C. Pawar, 1985: Climatological studies of thunderstorm to the west and east of the western ghats in the State of Maharashtra and Goa: Part I. Mausam, Vol. 107.

Price, C., and D. Rind, 1994: Modeling and global lightning distributions in a general circulation model. Mon. Wea. Rev., 122, 1930-1939.

Raman, P. K., and K. Raghavan, 1961: Diurnal variation of thunderstorm in India during different seasons. Indian J. Meteorol. Geophys., 12, 1, 115130.

Rao, K. N., and P. K. Raman, 1961: Frequency of days of thunder in India. Indian J. Meteorol. Geophys., 12, 103-108.

Rao, K. N., C. E. J. Dainel, and K. G. Pejabi, 1971: India Met. Dep. Pre-Publ. Sci. Rep. No. 154.

Rust, W. D., and R. J. Doviak, 1982: Radar research on thunderstorm and lightning. Nature, 297, 461468.

Saunders, C. P. R., W. D. Keith, and R. P. Mitzeva, 1991: The effect of liquid water thunderstorm charging. J. Geophys. Res., 96, 11007-11017.

Sivaramkrishnan, T. R., 1990: An analytical study of thunderstorm over Sriharikota. Mausam, 41, 489491.

Sohoni, V. V., 1931: Thunderstorm of Calcutta, 19261990. Scientific Notes, Vol. 1, 5, 26-36.

Takahashi, T., 1990: Near absence of lightning in torrential rainfall-producing Micronesian thunderstorms. Geophys. Res. Lett., 17, 2381-2384.

Williams, S. D., 1961: Frequency of thunderstorms in south India. Indian J. Meteorol. Geophys., 12, 131-133.

Williams, E. R., 1989: The tripole structure of thunderstorms, J. Geophys. Res., 94, D11, 13151-13167.

Williams, E. R., M. E. Weber, and R. E. Orville, 1989: The relationship between lightning type and convective state of thunder cloud. J. Geophys. Res., 94, 13213-13220.

Williams, E. R., 1992: The Schumann resonance: A global tropical thermometer. Science, 256, 1184 1187.

Williams, E. R., S. A. Rutledge, S. G. Geotis, N. Renno, E. Rasmusson, and T. Rickenbach, 1992: A radar and electrical study of tropical hot towers. $J$. Atmos. Sci., 49, 1386-1395.

Williams, E. R., and N. Renno, 1993: An analysis of the conditional instability of the tropical atmosphere, Mon. Wea. Rev., 121, 21-36.

Williams, E. R., 1994: Global circuit response to seasonal variation in global surface air Temperature, Mon. Wea. Rev., 122, 1917-1929.

Williams, E. R., 1997: Global circuit response to temperature on distinct time scales: A status report, p. 113, Parsons Laboratory, Mass. Inst. of Technol. Cambridge, Mass.

Williams, E. R., T. Chan, and D. J. Boccippio, 2004: Islands as miniature continents: Another look at the land-ocean lightning contrast. J. Geophys. Res., 109, D16206.

Zipser, E. J., 1994: Deep cumulonimbus cloud systems in the tropics with and without lightning, Mon. Wea. Rev., 122, 1837-1851. 